\title{
Multidisciplinary Research Opportunities: Need of the Hour
}

\section{Jagadevappa Patil}

VT's Shivajirao S Jondhle College of Pharmacy, Asangaon-412 601, Thane, Maharashtra, India

*Corresponding author: Jagadevappa Patil, VT's Shivajirao S Jondhle College of Pharmacy, Asangaon-412 601, Thane, Maharashtra, India, Tel: 9448816812; E-mail: pharmajspatil@gmail.com

Received date: February 04, 2016; Accepted date: February 05, 2016; Published date: February 08, 2016

Copyright: (c 2016 Patil J. This is an open-access article distributed under the terms of the Creative Commons Attribution License, which permits unrestricted use, distribution, and reproduction in any medium, provided the original author and source are credited.

\section{Introduction}

Multidisciplinary research is said to be a research when experts from diverse grounds work together on a common theme within the limits of their own discipline, they are said to adopt a multidisciplinary approach. However, if they restrict their work to these limits they may not continue further to achieve the intended results. It requires them to bring themselves to the suburbs of their own fields to form new concepts and create an entirely new, interdisciplinary pitch. An interdisciplinary team involved in the research must develop sufficient faith and mutual assurance in order to transcend disciplinary limits and adopt a more holistic approach. Information is usually conveyed through mutual communications. The research results of all the individual disciplines are surely applied to the betterment of mankind. Meticulousness is vital for the communication in all the research fields to be applied to the betterment of mankind. To bring out the better understanding between multidisciplinary team members having different background of thinking, it necessitates minimize the gap and maximize the mutual communication. The tools such as languages, mathematical appliances etc., will definitely help the team members of different background to work on a common platform. For example, the research in biomedical engineering [1,2] covers diverse fields other than engineering such as biology, medicine and pharmacy, and hence, the communication between the team members is very much important to achieve the successful research results.

\section{Multidisciplinary Approach}

To proceed with multidisciplinary research project by stalwartly expert team, it is much necessary to evaluate the infrastructural facilities available at the place of work. The traditional basic science departments in almost all stalwart institutes are needed to update the advanced infrastructure for avoiding the serious hindrance due to outdated facilities and to vigorously foster the interaction essential in multidisciplinary research. For developing strong future research biologists, it is necessary to renovate undergraduate educational curriculum by incorporating mathematics, physics, chemistry, computer science, and engineering and pharmaceutical sciences to focus on future multidisciplinary research. Hence, it is essential for all of us to renovate our skill and make it to be able to work effectively in multidisciplinary teams. The multidisciplinary approach is one of the hottest topics worldwide in the health care research field which can be evidenced by the results of search through google yielded more than 50 lakhs hits. Most of the well-known Universities of the world are involved in multidisciplinary research with a collaborative group of pharmacists, biomedical scientists, internists, and clinical scientists who accompaniment each other in both qualitative and quantitative endeavors with the objective to recruit and accomplish collaborative research in medicine and other clinical health care areas. Many famous School of medicine in the world are extending support for translational research and encouraging the talents of multidisciplinary research team comprised of various fields such as clinical epidemiology, health services research, health education, psychosocial science, data analysis and computer programming, biostatistics, measurement theory, decision analysis, survey research, operations research and health economics, sampling and program evaluation, including cost-benefit and cost-effectiveness analysis, and medical informatics. Most of these collaborative research teams are mainly focusing on the development of nanotechnology based drug delivery systems for the treatment of major diseases such as cancer and diabetes. On the other hand these teams are also working on diverse health care fields such as tissue engineering and regenerative medicines including transplant biology, cell biology, gene therapy, gene expression, bioactive materials, imaging, sensors, immunology, orthopedics and cardiovascular surgery.

\section{Purpose of Multidisciplinary Research}

Most of the time the complicated research problems cannot be solved by a particular discipline and it necessitates the collaboration of people of diverse expertise across a range of discipline together to achieve the research goal. Many a times any individual research member or an individual discipline often develop a shaft dream and may feel difficult to imagine beyond the routine knowledge. By making a collaborative team of multidisciplinary experts it becomes conceivable to think beyond the routine knowledge. So, multidisciplinary research connects the members of diverse expertise to solve a particular research problem. For example, identification of approximately 25,000 genes in human DNA would not have been achieved without the help of engineers, bioinformatics and other scientists.

\section{Conclusion}

While begin with such multidisciplinary research projects, emphasize is to be made to constitute the research team reasonably as small as possible, so that there are fair chances of success. The success of such research projects also depends on preparation of memorandum of understanding between the team members with various procedures such as defining the rationale for the work to be undertaken, summary of the work, defining the responsibilities of team members with specific contributions, time bond, procedure for dissemination of work outcome, agreement on publication process and possible commercialization of the outcome. These all exercises may definitely help to solve the major research problems through multidisciplinary approach. 
Citation: Patil J (2016) Multidisciplinary Research Opportunities: Need of the Hour. J Pharmacovigil 4: 147. doi:10.4172/2329-6887.1000e147

Page 2 of 2

\section{References}

1. Linsenmeier RA (2003) What Makes a Biomedical Engineer? Defining the Undergraduate Biomedical Engineering Curriculum. IEEE Engineering in Medicine and Biology Magazine 23: 32-38.
2. Hashimoto S, Ohsuga M, Yoshiura M, Tsutsui H, Akazawa K, et al. (2007) Parallel Curriculum of Biomedical Engineering Subjects with Rotational Experimental Project for Interdisciplinary Study Field. Proc 11th World Multiconference on Systemics Cybernetics and Informatics 4: 39-44. 